\title{
PRESCRIPTION PATTERN AND COST OF ILLNESS (COI) OF INFLAMMATORY BOWEL DISEASE (IBD) IN A TERTIARY CARE HOSPITAL
}

\author{
MIRZA MISBA ALI BAIG, SARA FATIMA, MEHRUQ FATIMA, SHAHEDA SIDDIQUI, SYED AMIR ALI, MD NOMAAN ILYAS \\ Deccan School of Pharmacy, Darussalam, Aghapura, Nampally, Hyderabad 500001 \\ Email: syed.aamir12@gmail.com \\ Received: 09 Apr 2016 Revised and Accepted: 27 0ct 2016
}

\begin{abstract}
Objective: Treatment of Inflammatory Bowel disease (IBD) centers on agents used to relieve inflammatory process. None of the drugs used for IBD are curative; at best they serve to control the disease process. The potentially high costs of care associated with inflammatory bowel disease (IBD) are recognised. The Objective of the present study was to find the Prescription pattern and cost of illness (COI) of IBD in a Tertiary care Hospital.
\end{abstract}

Methods: 20 IBD patients, in the order they approached the gastroenterology department, were enrolled in the study. Data regarding medication, hospitalisation, physician office visit, diagnostic costs, travel cost, the cost incurred by caregivers, work and non-work days lost were obtained. The cost of medications and other healthcare services was determined. The study was approved by the Institutional ethics committee.

Results: The average cost (direct and indirect) per patient for six months was 26,394Rs. Drugs and medical supplies costs (65\%) ranked first in the direct costs category followed by Diagnostic costs (18\%), hospitalisation costs (15\%) and lastly physician office visit costs (2\%). On the other hand, Cost incurred by caregivers accounted for $45 \%$ of the total indirect costs followed by work and nonworking days lost (43\%) and finally Travel costs (2\%). Commonly prescribed drugs were corticosteroids and aminosalicylates followed by mucosal protectants, antibiotics and antiemetics. The most preferred route of drug administration was intravenous followed by oral.

Conclusion: The average COI (direct and indirect) of IBD per patient for six months was 26,394Rs. Drugs and medical supplies accounted for largest contributions to the overall economic impact of IBD on the Healthcare system. Commonly prescribed drugs were corticosteroids and aminosalicylates followed by mucosal protectants, antibiotics and antiemetics. This study represents one of the very few studies conducted on COI of IBD. Large scale studies on economic research are required to further ascertain the impact of Rival therapies and management strategies for IBD.

Keywords: IBD, COI, Prescription Pattern, Pharmacoeconomics

(c) 2017 The Authors. Published by Innovare Academic Sciences Pvt Ltd. This is an open access article under the CC BY license (http://creativecommons.org/licenses/by/4. 0/)

DOI: http://dx.doi.org/10.22159/ijpps.2017v9i1.14248

\section{INTRODUCTION}

Inflammatory Bowel disease (IBD) comprises of Ulcerative Colitis, Crohn's Disease and Indeterminate colitis. It is the chronic, idiopathic, immune mediated, relapsing, inflammatory condition of the gastrointestinal tract $[1,2]$. Standard medical therapy includes corticosteroid in the acute phase, mesalazine or immunomodulators to maintain remission and biological agents for refractory and/or severe cases [3]. Lack of curative treatment makes lifelong treatment and Surgery the only options available for IBD. Ultimately, Hospitalization and surgery contribute to more than half of the economic burden of IBD to the society [4-7]. The quality of life of the patient is severely compensated with continuing symptoms, reduction in the ability to work, social stigma, bathroom access issues, difficulty with physical intimacy and restriction in career choices [8].

Initially, IBD was considered to be the disorder of developed countries, but recent epidemiological data suggest a shift towards developing nations including Asian countries $[9,10]$. The financial burden of IBD can be divided into direct and indirect costs. Direct medical costs include expenses for hospitalisations, physician services, prescription drugs, over-the-counter drugs, skilled nursing care, diagnostic procedures, and other healthcare services. Indirect costs are the value of lost earnings or productivity, the value of leisure time lost, the cost incurred by caregivers and travel costs [11]. Indian Data on Cost of Illness of IBD is scarce. Moreover, given the rising prevalence of IBD worldwide, it is urgently necessary to understand its economic burden and to provide more robust evaluations of health care interventions designed to reduce its incidence and impact. Thus the present study was aimed at finding the cost of illness and prescribing pattern of IBD.

\section{MATERIALS AND METHODS}

Methods

This prospective, observational study was performed on inpatients and outpatients of Gastroenterology Department of a tertiary care Hospital in Hyderabad. Due to time constraints, only 20 IBD patients were included. Patients with confirmed IBD, those willing to give written or verbal informed consent and above $15 \mathrm{y}$ of age were only included in the study. Pregnant women and children were excluded from the study.

\section{Ethical approval}

The study was approved by the Institutional Ethics Committee of the Hospital.

\section{Data collection}

This observational, prospective study collected demographic, clinical, and economic data of IBD patients. The data was collected from patient's treatment chart/case sheets, lab reports and from patient's attendees. All subjects gave informed consent to participate in the study and allowed the use of their personal data for research purposes. Patients were enrolled consecutively, according to the order in which they presented to the gastroenterologist for consultation.

\section{Data analysis and statistical methods}

Costs are presented to the nearest Indian rupee. Mean patient costs were taken into consideration for the calculation of total costs. Descriptive statistics were used to characterise the study population. Continuous variables were presented as means whereas categorical variables were presented as numbers and percentages. 


\section{Results}

\section{Sociodemographic and clinical characteristics}

Among 20 patients, 8 patients were male, and 12 patients were female. The most common age group of IBD patients was 1625 years. $30 \%$ of the population had income in the range of 20,000 Rs to 30,000 Rs. $25 \%$ of the patients were unskilled (table 1 ). On the basis of the diagnosis, total patients were categorised into two groups-Ulcerative Colitis and Crohn's Disease with percentage population of 95 and 5 respectively. Major presenting complaints in Ulcerative Colitis were abdominal pain, frequent bowel movement and vomiting while in Crohn's Disease, it was blood per rectum (table 2). 65\% of the patients had Diabetes Mellitus as co-morbid condition (table 3).

\section{Medications}

In the present study, the majority of the patients (84.2\%) with ulcerative colitis were treated with corticosteroid (dexamethasone) in combination with 5-aminosalicylic acid (mesalamine). We also observed the growing interest in probiotics approaches for IBD. $80 \%$ of patients were prescribed with probiotics (lactobacillus). Antibiotics especially, metronidazole was prescribed in $85 \%$ of total patients. Other antibiotics which were prescribed were imipenem and ticarcillin+clavulanic acid. Mucosal defence agent (sucralfate) was prescribed in $95 \%$ of total patients (table 4). Most common route of administration was intravenous followed by oral (table 5).

\section{Cost of Illness (COI)}

The average cost of IBD treatment was between Rs.11000-30,000. About $75 \%$ of the total patients had an expense between these ranges. Direct Cost was notably higher than indirect costs. Among the direct costs, drugs and medical supplies had the major contribution of $65 \%$, followed by diagnostic costs $(18 \%)$, hospitalisation costs $(15 \%)$ and physician office visit costs $(2 \%)$. On the other side, cost incurred by caregivers had the major contribution of $45 \%$ to the indirect costs followed by work and nonwork days lost (43\%) and lastly, travel costs $(2 \%)$. The total direct and Indirect cost per patient for 6 mo was found to be 26,394Rs (table 6).

Table 1: Sociodemographic characteristics of the patients

\begin{tabular}{ll}
\hline Characteristic & IBD(n=20) \\
\hline Male/female & $\mathbf{8 / 1 2}$ \\
Age(years) & \\
$16-25$ & 8 \\
$26-35$ & 4 \\
$36-45$ & 5 \\
$46-55$ & 1 \\
$56-65$ & 3 \\
Income(Rupees) & \\
$<10,000$ & 25 \\
$10,000-19,999$ & 15 \\
$20,000-29,999$ & 30 \\
$30,000-39,999$ & 20 \\
$>40,000$ & 10 \\
Occupation & \\
Unskilled & 25 \\
Semiskilled & 15 \\
Skilled & 15 \\
Clerical & 5 \\
Administrators & 5 \\
Managers & 15 \\
Executives & 15 \\
Homemakers & 5 \\
\hline
\end{tabular}

Table 2: Distribution of patients based on presenting complaints

\begin{tabular}{llll}
\hline S. No. & Complaints & Sex & No. of patients \\
\hline 1. & Abdominal pain & $\mathrm{M}$ & 0 \\
& & $\mathrm{~F}$ & 2 \\
2. & Blood per rectum & $\mathrm{M}$ & 2 \\
& & $\mathrm{~F}$ & 1 \\
3. & Frequent bowel movement with blood in stools & $\mathrm{M}$ & 0 \\
& & $\mathrm{~F}$ & 2 \\
4. & Vomiting with loose stools & $\mathrm{M}$ & 2 \\
& & $\mathrm{~F}$ & 1 \\
5. & Abdominal pain with vomiting & $\mathrm{M}$ & 0 \\
& & $\mathrm{~F}$ & 2 \\
6. & Abdominal pain and frequent bowel movement with blood in stools & $\mathrm{M}$ & 2 \\
& & $\mathrm{~F}$ & 2 \\
7. & Frequent bowel movement with blood and mucuos in stool & $\mathrm{M}$ & 1 \\
& & $\mathrm{~F}$ & 1 \\
& Abdominal pain and frequent bowel movement & $\mathrm{M}$ & 1 \\
\end{tabular}

Table 3: Distribution of patients based on co-morbidities

\begin{tabular}{llll}
\hline S. No. & Co-morbidities & Sex & No. of patients \\
\hline 1. & Diabetes mellitus & $\mathrm{M}$ & 2 \\
& & $\mathrm{~F}$ & 2 \\
2. & Hypertension & $\mathrm{M}$ & 0 \\
& & $\mathrm{~F}$ & 1 \\
3. & Acid peptic disease & $\mathrm{M}$ & 1 \\
& & $\mathrm{~F}$ & 1 \\
5. & Arthritis & $\mathrm{M}$ & 0 \\
& & $\mathrm{~F}$ & 1 \\
6. & Internal hemorrhoids & $\mathrm{M}$ & 1 \\
7. & & $\mathrm{~F}$ & 2 \\
& Constipation & $\mathrm{M}$ & 0 \\
\hline
\end{tabular}


Table 4: Drugs majorly used in inflammatory bowel disease

\begin{tabular}{llll}
\hline S. No. & Generic name & Number of patients \\
\cline { 2 - 3 } & & Ulcerative colitis & Crohn's disease \\
\hline 1. & Dexamethasone & 16 & 1 \\
2. & Dexrabeprozole & 9 & 1 \\
3. & Imipenem & 6 & 0 \\
4. & Lactobacillus & 15 & 1 \\
5. & Loperamide & 4 & 0 \\
6. & Magaldrate & 7 & 1 \\
7. & Mesalamine & 14 & 1 \\
8. & Metronidazole & 16 & 1 \\
9. & Ondensetron & 12 & 1 \\
10. & Rabeprazole & 10 & 1 \\
11. & Sucralfate & 18 & 1 \\
12. & Ticarcillin-clavulanate & 11 & 0 \\
\hline
\end{tabular}

Table 5: Distribution of drugs based on route of administration

\begin{tabular}{llll}
\hline S. No. & Route of administration & Ulcerative colitis & Crohn's disease \\
\hline 1. & Nebulization & 1 & 0 \\
2. & Oral (tablets) & 40 & 2 \\
3. & Oral (syrups) & 33 & 2 \\
4. & Parentrals & 100 & 5 \\
5. & Rectals & 10 & 0 \\
\hline
\end{tabular}

Table 6: Total cost involved in inflammatory bowel disease (IBD)

\begin{tabular}{lll}
\hline Direct costs & Total cost (\%) & Cost per patient (Rs.) \\
\hline Diagnostic costs & $81033(18)$ & 4051 \\
Drugs and medical supplies & $299404(65)$ & 14970 \\
Physician office visits & $9890(2)$ & 495 \\
Hospitalization & $71950(15)$ & 3598 \\
Indirect costs & & 382 \\
Travel costs & $7636(12)$ & 1418 \\
Work and nonwork days lost & $28350(43)$ & 1480 \\
Cost incurred by caregivers & $29600(45)$ & 26394 \\
Total (direct and Indirect) cost per patient for 6 mo & & 52788 \\
Expected total direct cost per patient for 1y & & \\
\hline
\end{tabular}

\section{DISCUSSION}

Since the incidence and prevalence of IBD is rising worldwide, there will be a subsequent increase in the economic impact on the healthcare system and the economy as a whole. The present study provides a crosssectional view of resource utilisation of IBD patients in a tertiary care Hospital. Although single centre studies with less number of patients lack external validity, this study is one of the very few studies conducted on cost burden of IBD treatment. Practice patterns may vary among hospitals resulting into differences in the costs of IBD treatment. Another factor that leads to variation in the costs is the severity of IBD. A small group of severely ill patients constitutes a major proportion of costs of a large group of patients $[14,15]$.

Till 2000, Hospitalization and surgery were the major cost drivers in IBD, but in our study, medication use represented the major source of Healthcare costs. In a study conducted by Bassi Et al., medical and surgical hospitalization contributed to over half of total costs, but only $18 \%$ of healthcare costs in CD and $24 \%$ in UC was due to direct medication expenditure [5]. This contrasts with data from our study, in which medication costs accounted for up to $65 \%$ of the healthcare costs for IBD. Similar trends can be seen in study conducted by Odes et al., who reported that more than half of the costs were due to hospitalization and surgery, while only $30 \%$ of the cost were due to medication use [7].

No patient in our cohort received infliximab and our data, therefore, provide vital baseline information about the costs associated with established therapies for IBD. The potential impact of novel immunomodulation drugs (e. g, anti-tumour necrosis factor therapy) on the profile of costs for IBD remains to be determined.
Indirect costs often remain unrecognised but in fact sometimes even exceed direct costs. We evaluated indirect costs by means of a crosssectional survey. Indirect costs included Costs incurred by caregivers (45\%), work and nonwork day's productivity losses $(43 \%)$ and lastly travel costs $(12 \%)$. We report that productivity losses due to work and non-work days lost and cost incurred by caregivers accounted for approximately $90 \%$ of the total indirect costs. On similar lines, A German study reported that $49 \%$ of the total costs were due to work disability in $\mathrm{CD}$ and $32 \%$ in UC, respectively [12]. Similarly, a Swedish study reported that $36 \%$ of the total costs of IBD were due to work disability [13].

In conclusion, the present study is the first to show treatment reality of IBD in Hyderabad, Telangana. The average COI (direct and indirect) of IBD per patient for six months was 26,394Rs. Drugs and medical supplies accounted for largest contributions to the overall economic impact of IBD on the Healthcare system. Commonly prescribed drugs were corticosteroids and aminosalicylates followed by mucosal protectants, antibiotics and antiemetics. Large scale studies on economic research are required to further ascertain the impact of Rival therapies and management strategies for IBD.

\section{CONFLICT OF INTERESTS}

\section{Declared none}

\section{REFERENCES}

1. J Satsangi, MS Silverberg, S Vermeire, JF Colombel. The montreal classification of Inflammatory bowel disease: controversies, consensus, and implications. Gut 2006;55:749-53.

2. C Abraham, JH Cho. Inflammatory bowel disease: N Engl J Med; 2009. p. 2066-78. 
3. Mario Guslandi. A natural approach to the treatment of inflammatory bowel disease. Br J Clin Pharmacol 2008;65:468-9.

4. Cosnes J, Cattan S, Blain A, Beaugerie L, Carbonnel F, Parc R, et al. Long-term evolution of disease behaviour of Crohn's disease. Inflamm Bowel Dis 2002;8:244-50.

5. Bassi A, Dodd S, Williamson P, Bodger K. Cost of illness of inflammatory bowel disease in the UK: a single centre retrospective study. Gut 2004;53:1471-8.

6. Juan J, Estiarte R, Colomé E, Artés M, Jiménez FJ, Alonso J. Burden of illness of crohn's disease in spain. Dig Liver Dis 2003;35:853-61.

7. Odes S, Vardi H, Friger M, Wolters F, Russel MG, Riis L, et al. Cost analysis and cost determinants in a European inflammatory bowel disease inception cohort with $10 \mathrm{y}$ of follow-up evaluation. Gastroenterol 2006;131:719-28.

8. Rocchi A, Benchimol EI, Bernstein CN, Bitton A, Feagan $\mathrm{B}$, Panaccione R, et al. Inflammatory bowel disease: a canadian burden of illness review. Can J Gastroenterol 2012;26:811-8.

9. BD Lovasz, PA Golovics, Z Vegh, PL Lakatos. New trends in inflammatory bowel disease epidemiology and disease course in Eastern Europe. Dig Liver Dis 2013;45:269-76.

10. Molodecky NA, Soon IS, Rabi DM, Ghali WA, Ferris M, Chernoff $\mathrm{G}$, et al. Increasing incidence and prevalence of the inflammatory bowel diseases with time, based on systematic review. Gastroenterology 2012;142:46-54.

11. www.ccfa.org. Crohn's and Colitis foundation of America. [Last accessed on 3 May 2016]

12. Stark R, Konig HH, Leidl R. Costs of inflammatory bowel disease in Germany. Pharmacoeconomics 2006;24:797-814.

13. Blomqvist P, Ekbom A. Inflammatory bowel diseases: health care and costs in Sweden in 1994. Scand J Gastroenterol 1997;32:1134-9.

14. Paweł W Petryszyn, Izabela Witczak. Costs in inflammatory bowel diseases. Prz Gastroenterol 2016;11:6-13.

15. Feagan BG, Vreeland MG, Larson LR, Bala MV. The annual cost of care for Crohn's disease: a payor perspective. Am J Gastroenterol 2000;95:1955-60.

\section{How to cite this article}

- $\quad$ Mirza Misba Ali Baig, Sara Fatima, Mehruq Fatima, Shaheda Siddiqui, Syed Amir Ali, Md Nomaan Ilyas. Prescription pattern and cost of illness (COI) of inflammatory bowel disease (IBD) in a tertiary care hospital. Int J Pharm Pharm Sci 2017;9(1):44-47. 